Please do not remove this page

RMIT

UNIVERSITY

\title{
Numerical analysis of damage progression and strength of countersunk composite joints
}

Chishti, Maajid; Wang, Chun; Thomson, Rodney; Orifici, Adrian

https://researchrepository.rmit.edu.au/esploro/outputs/9921858689901341/filesAndLinks?institution=61RMIT_INST\&index=null

Chishti, M., Wang, C., Thomson, R., \& Orifici, A. (2012). Numerical analysis of damage progression and strength of countersunk composite joints. Composite Structures, 94(2), 643-653.

https://doi.org/10.1016/j.compstruct.2011.08.030

Document Version: Accepted Manuscript

Published Version: https://doi.org/10.1016/j.compstruct.2011.08.030

Repository homepage: https://researchrepository.rmit.edu.au

(c) Copyright 2011 Elsevier B.V., All rights reserved.

Downloaded On 2023/04/26 20:38:48 +1000

Please do not remove this page 
Thank you for downloading this document from the RMIT Research Repository.

The RMIT Research Repository is an open access database showcasing the research outputs of RMIT University researchers.

RMIT Research Repository: http://researchbank.rmit.edu.au/

\section{Citation:}

Chishti, M, Wang, C, Thomson, R and Orifici, A 2012, 'Numerical analysis of damage progression and strength of countersunk composite joints', Composite Structures, vol. 94, no. 2, pp. 643-653.

See this record in the RMIT Research Repository at:

http://researchbank.rmit.edu.au/view/rmit:12869

Version: Accepted Manuscript

Copyright Statement: @ Copyright 2011 Elsevier B.V., All rights reserved

Link to Published Version:

http://dx.doi.org/10.1016/j.compstruct.2011.08.030 


\title{
Numerical Analysis of Damage Progression and Strength of Countersunk Composite Joints
}

\author{
Maajid Chishti ${ }^{\text {a }}$, Chun H. Wang ${ }^{\text {a, }}$, Rodney S. Thomson ${ }^{\text {b }}$, Adrian C. Orifici ${ }^{\text {a, }}$, \\ ${ }^{a}$ RMIT University, School of Aerospace, Mechanical and Manufacturing Engineering, \\ GPO Box 2476, Melbourne, Victoria 3001, Australia \\ * corresponding author: adrian.orifici@rmit.edu.au, fax +6139925 6108 \\ ${ }^{\mathrm{b}}$ Cooperative Research Centre for Advanced Composite Structures Ltd, \\ 506 Lorimer Street, Fishermans Bend, Victoria 3207, Australia
}

\begin{abstract}
A numerical investigation is conducted into the damage progression and strength of bolted joints between fibre-reinforced composite laminates using countersunk fasteners. Experimental tests were previously conducted on a bearing test specimen and countersunk fastener single-lap joints. In this work, computational models are developed for Abaqus/Explicit, with continuum shells employed to model in-plane ply failure. The boltnut assembly is modelled with rigid elements, and the models account for bolt torque and frictional contact. The material properties required in the computational model are determined from standard tests, with the compression fracture toughness of composite plies calibrated against experimental data from the bearing test. The analysis approach captures the load-carrying capability of all configurations, and provides reasonable accuracy in predicting damage patterns. The effects of bolt torque, clearance and countersink height
\end{abstract}


ratio are investigated, and the analysis results compare well with experimental findings. Furthermore, the analysis provides rich insight into the damage progression and joint behaviour at the ply level, with the in-plane and through-thickness damage patterns mapped for increasing applied load. Delamination is incorporated using a cohesive element layer at the start of the countersunk region, though has minimal influence on damage progression and load-carrying capability, which agrees with the experimental results.

Keywords: Countersunk joints, bearing, progressive damage, finite element analysis

\section{Introduction}

Despite the many advantages of adhesive bonding, bolted joints are still used in aerospace structures because of the ease of assembly/disassembly and airworthiness certification. Countersunk bolts are used where surface flushness is required, such as for aerodynamic reasons. The application of countersunk bolts produces high stress concentrations and complicated three-dimensional (3D) stress fields. For design and analysis of joints, validated analysis methodologies are required that are capable of capturing the initiation and progression of the key damage mechanisms.

In previous studies on fibre-reinforced composite laminates, experimental testing was conducted on a bearing test specimen and countersunk single-lap joints $[1,2]$, summarised in Table 1, Table 2 and Figure 1. There was one configuration of bearing test with a straight-edge hole, and various configurations of single-lap joint specimens with countersunk bolts. The labelling of the single-lap joint specimens refers to the variations in bolt torque (BT), bolt hole clearance (CL) and countersink height ratio (HT) investigated. 
As examples, specimens BT_0, CL_240 and HT_0.56 refer respectively to single-lap joint specimens with $0 \mathrm{~N}$ m bolt torque, $240 \mu \mathrm{m}$ of bolt hole clearance, and a countersink height (h) to total laminate thickness $(t)$ ratio $h / t=0.56$.

The bearing failure of the specimens was characterised by intralaminar and interlaminar shear cracks, which were caused by fibre and matrix failure predominantly in compression. Delamination occurred for some configurations, and was primarily located at the start of the countersunk region, though considered to have only minor influence on the joint behaviour. The effects of the countersink geometry and various joint parameters were studied using the load-carrying behaviour of the joint, and the damage mechanisms observed from post-test microscopy.

In this work, the same specimens are investigated using numerical analysis with the commercial finite element (FE) code Abaqus/Explicit [3]. An analysis methodology is developed and validated, and the key issues of damage mode, material properties and contact modelling are discussed. The results of the numerical analysis are presented with a focus on providing a more detailed insight into the progressive failure process, and the influence of the countersink joint parameters.

\section{Methodology}

\subsection{Damage modes and element types}

Capturing the damage modes seen in the experiment is a key requirement of the analysis methodology. To characterise the fibre and matrix failure modes, the damage model for in-plane ply failure of fibre-reinforced composites was applied [3, 4]. In this 
approach, four damage modes associated with tension and compression failure of the fibre and matrix are used to trigger reductions in the elastic properties, with the amount of reduction being controlled by damage associated with each of these damage modes. For delamination, cohesive elements were applied, which incorporate a traction-displacement material law defined by initiation stresses and fracture toughness in the three orthogonal crack opening modes.

The selection of element type is important in this respect, in needing to balance the requirements of the analysis with the capabilities of the analysis code. Continuum shell elements were applied for the composite laminates, as these were capable of representing the joint geometry accurately so that the contact conditions could be captured. Furthermore, in comparison with solid elements, continuum shells are more computationally efficient, and critically, are compatible with the damage model for in-plane ply failure. Zerothickness cohesive elements were used to model delamination at the interface between composite plies. One cohesive element layer was applied at the start of the countersunk hole geometry, as this was the location of primary delamination seen experimentally. The bolt-nut assembly was modelled using rigid elements, as no failure of these items was observed in experiment.

\subsection{Material properties}

Appropriate material properties are critical for any analysis, with regards to both elastic properties and the properties specifically required for any damage models. Each fabric ply was modelled as two unidirectional (UD) plies that represented the stiffness and strength of the woven ply. This choice was determined by the capabilities of the analysis 
code, as no damage models are currently available specifically for fabric materials. The elastic material properties are given in Table 2, and were calculated from fibre and matrix properties and the procedures in Ref. [5], and were further calibrated using results for the bearing test.

For the in-plane ply damage model properties, the experimental results of the bearing test were used to calibrate the fracture toughness for fibre compression failure, $G_{f c}$. The bearing test was used for calibration in this manner as no standards currently exist for this material property. Whilst some authors have used other specimens to determine this value $[6,7]$, it was considered that the bearing failure mode represents a unique combination of energy absorbing damage mechanisms, so that the characterisation specimen needs to represent the failure process as closely as possible. The results of the calibration process are shown in Figure 2, where the influence of $G_{f c}$ on the load-displacement behaviour can be seen. From these results, a fibre compression fracture toughness of $55 \mathrm{~kJ} / \mathrm{mm}^{2}$ was taken. The fracture toughness values for the other damage modes were taken from Ref. [7], though the fibre tension fracture toughness was scaled using the calibrated $G_{f c}$ value. Although these fracture toughness values were determined from UD tape laminates, as they correspond to in-plane fibre and matrix failure, it was considered that these values are largely independent of the fibre architecture. All fracture toughness values are summarised in Table 4.

For the cohesive element material law in each orthogonal direction, the initial stiffness and fracture toughness values were taken from the recommendations of other authors with identical or similar material systems $[8,9]$. The failure initiation strength was 
determined according to the recommendations in Ref. [10]. These recommendations ensure that the cohesive degradation occurs over a "process zone" corresponding to a minimum number of elements, which was taken as three based on the work of other authors [8]. A summary of cohesive element material properties and references is given in Table 5 .

\subsection{Contact modelling and bolt torque}

The complex set of contact conditions between the upper laminate, lower laminate, bolt and nut is a key aspect in representing the joint behaviour accurately and allowing for the introduction of bolt torque. Node-based contact was implemented on all contacting interfaces, which are shown in Figure 3. Friction was modelled at all interfaces, except for between the nut and bolt, which were tied following application of the torque as described below. A friction coefficient of 0.2 was applied, following recommendations in Ref. [11] and other authors.

Bolt torque was introduced in pre-loading steps as illustrated in Figure 3, which attempted to mirror the manufacturing procedure where possible. As shown in Figure 3, the bolt was pushed into the nut and tied with contact constraints whilst both laminates and the nut were fixed. The displacement of the bolt was calculated based on the applied torque, bolt diameter and torque coefficient as described by Ref. [12], where a displacement of $1.81 \mu \mathrm{m}$ was found to represent a torque of $2.0 \mathrm{~N} \mathrm{~m}$. Following this, the bolt-nut assembly was fixed whilst the laminate was left unrestrained, and the final load step applied the displacement load.

\subsection{Model and analysis parameters}


Models were created in Abaqus/Explicit 6.9 [3] for the bearing test and single-lap joint configurations. The in-plane and through-thickness mesh densities were determined using mesh sensitivity investigations. The mesh and boundary conditions are shown in Figure 4(a) and Figure 5, and the in-plane mesh variants used for mesh studies are shown in Figure 4(b). In the through-thickness direction, the bearing test models used 32 elements, and the single-lap joint models used 4 elements for the lower laminate and between 2 and 4 elements for the upper laminate depending on the hole geometry. The in-plane mesh sensitivity analysis results are shown in Figure 6, where the convergence for the higher density mesh results is clear. Similar convergent behaviour was observed for variations in through-thickness mesh density.

A mass scaling factor of 100 was applied, and was determined as suitable using parametric studies. Hourglass control was implemented using the "combined" approach, with default parameters [3]. The maximum damage index is the upper limit of the elastic property knockdown, and has important implications for the stability of the simulation with material failure. A maximum damage index of 0.985 was determined as suitable using parametric studies.

The bearing load was calculated according to recommendations in the ASTM standard [13], which involves determining the load associated with bearing displacement that is $4 \%$ of the bolt diameter. In the experimental testing, the displacement was measured from tabs on either side of the bolt, instead of directly on the bolt as dictated by the standard [13], as the apparatus for this measurement was not available. In the numerical analysis, the displacement between the tab locations was also measured, to provide the 
closest comparison with the experimental results. The applied stress was determined by dividing the applied load by the bearing area $(D \times t)$. The applied stress versus extensometer displacement (stress-displacement) result is shown as a measure of overall load-carrying capability. The cylindrical coordinate system shown in Figure 7 was also used, where stresses in the radius $(r)$ direction at $1.5 \mathrm{kN}$ applied load were normalised by the maximum stress in the bearing test, $\sigma_{b, \max }$ at the same applied load. This normalised radial stress is plotted as a function of the angular coordinate $\theta$ for a given ply location.

\section{Results}

\subsection{Experimental and numerical comparison}

A comparison between the experimental and numerical results is shown for a selection of configurations in Figure 8 and Figure 9, and summarised for all configurations in Table 6. One aspect that is important for the numerical analysis is the convergence and stability. Initially a number of analyses were unable to complete due to stability issues associated with excessive element deformation following material failure. An example of this can be seen in Figure 8, where the analysis of the CL_440 specimen was not able to be completed to the same applied displacement as the experimental results. Despite this, all models were able to capture a significant portion of the progressive failure process in the non-linear region, such that the investigation of the key joint parameters was still possible. As such, some of the results for maximum stress in Table 6 are given for an applied displacement of $2 \mathrm{~mm}$.

From the results in Table 6, it can be seen that the analysis methodology gives close correlation with the experimental results for maximum stress, with less than $10 \%$ difference 
for all configurations except HT_0.64 (14\%). The close agreement is also seen in the stressdisplacement results in Figure 8, which also shows that the analysis methodology is capable of describing the effects of bolt torque, clearance and height ratio. The results for bearing stress do not compare as well, with around 20\%-30\% difference across all configurations. This is caused by the difficulty in capturing the joint stiffness in the linear region, as the bearing stress predictions were highly sensitive to this initial stiffness. This may be influenced by the method of applying bolt torque via bolt displacement, as the two configurations without bolt torque (the bearing test and the BT_0 single-lap joint) showed much better comparison for initial stiffness and bearing stress. Despite this particular aspect, the results demonstrate that the analysis methodology is able to capture the loadcarrying capability of the joint, and account for the effect of the damage progression.

A comparison between experimental and numerical through-thickness damage profiles is shown in Figure 9. The experimental micrograph shows the dense interlaminar and intralaminar shear cracking associated with bearing damage, as well as fraying and material loss at the damaged edge. The numerical results are presented using two approaches, which both show only the damage index associated with fibre compression failure. The image at the top of the figure shows an interrogation of the results at a ply-byply level, whilst the bottom image shows the "enveloped" maximum damage index within all plies in an element. The results show that the enveloped approach provides a slight overestimation and loss of ply-level detail. However, this approach still provides meaningful comparison and reasonable accuracy, and as it is much more rapid for post-processing through-thickness sections it is applied throughout the rest of this paper. Overall, the 
comparison between the experimental and numerical results in Figure 9 and those not shown demonstrated that the analysis methodology was capable of capturing the overall damage profile quite well.

\subsection{Effect of bolt torque}

In the experimental results shown in Table 6 and discussed in detail in Ref. [1], increasing bolt torque caused a significant increase in bearing stress, though only a small increase in ultimate stress. The effect of bolt torque was more pronounced between the finger-tight (BT_0) and moderate torque (BT_2.1) cases, than between the moderate and highly torqued (BT_4.2) joints. These trends were all captured well by the numerical analysis, as shown in Table 6.

With regards to the damage profile, a comparison between the three different bolt torque cases is shown in Figure 10 and Figure 11. The experimental investigation showed that increasing the torque reduced the length of bearing damage, whilst increasing its severity $[1,2]$. These trends are reflected in the through-thickness profile in Figure 10, where increasing the torque reduces the length of the damage region for the lower laminate, and increases the severity of damage, particularly in the upper laminate. The ply-level patterns in Figure 11 show that the application of torque increased the damage in the countersunk region, and reduced the damage at the shear plane for the upper laminate. The extent of damage around the hole was not significantly affected by increasing torque.

In the experimental investigation, delamination was seen to occur in the specimens investigating bolt torque only, and involved a single "primary" delamination initiating at 
the start of the countersink region. In the numerical analysis, a single layer of cohesive elements was applied at this location, and the results comparing the experimental results with numerical models with and without delamination are shown in Figure 12. These results show that the introduction of delamination led to a slight improvement in predictions, though the effect was only small. In Figure 13, the stress-displacement results for the numerical model with delamination are overlaid with the damage indices for fibre compression and delamination from elements at the hole edge. These results show that fibre compressive failure preceded the occurrence of delamination, and whilst delamination did occur, it did not show any significant influence on further fibre compression failure.

Overall, the inclusion of delamination in the numerical models had minimal effect of the behaviour of the joint, which agrees with the conclusions from the experimental investigation.

\subsection{Effect of bolt clearance}

The results in Table 6 show that the introduction of bolt hole clearance in the experimental specimens significantly decreased the bearing stress and stress measured at 2 mm displacement, both of which were well captured by the numerical models. The decrease in stress at $2 \mathrm{~mm}$ displacement was caused by the shift in stress-displacement results towards higher displacements for increasing clearance. This can be seen in Figure 8 in the results for the high clearance (CL_440) configuration, and was caused by the bolt needing to cross the bolt hole gap before load transfer could occur.

A summary of the damage profile for the specimens investigating bolt clearance is shown in Figure 14 and Figure 15. Experimental micrographs in Ref. [1, 2] showed that the 
introduction of clearance increased the damage at the shear plane, and caused a more localised damage pattern. These trends are clearly reflected in the numerical results, where the damage was seen to initiate earlier and become more concentrated towards the shear plane for increased clearance.

The change in damage behaviour with the introduction of clearance was found to be caused by the variation of contact area between the bolt and laminate. The numerical models showed that at moderate clearance (CL_240), there was a 7\% reduction in bolt contact area, and at high clearance (CL_440) a 9\% reduction. This meant that as the bolt hole clearance increases the bolt loads were increasingly being transferred through a smaller area, resulting in increased stresses and more localised damage. This is clearly shown in the radial stress distribution in Figure 16, where the introduction of clearance increased the stress in the central section by almost four times. These results also explain the larger difference in joint behaviour between the no clearance and moderate clearance cases, than between the moderate and high clearance configurations.

\subsection{Effect of countersink height ratio}

From the experimental results in Table 6, it is evident that increasing the relative size of the countersunk region from 0.56 (HT_0.56) to 0.64 (HT_0.64) had minimal effect on both bearing stress and stress at $2 \mathrm{~mm}$ displacement. However, further increasing the height ratio to 0.76 (HT_0.76) caused a change in the behaviour of the joint, where the character of the stress-displacement results was clearly different, and the stresses were significantly reduced. These trends were all captured very well by the numerical analysis. 
This change in the behaviour of the joints is associated with the increased degree of bending caused by increasing the relative size of the countersunk region. As the straightedge region carries the majority of loads, increasing the height ratio increases the load eccentricity through the countersunk region, promoting more bending. This trend is clearly shown in Figure 17, which compares numerical results for bending displacement for the different HT configurations. Although out-of-plane displacement was not measured experimentally, the magnitude of bending displacements was observed to be several times larger than the numerical predictions shown in Figure 17. This is despite the fact that the overall comparison between the experimental and numerical stress-displacement results was quite close, as shown in Figure 8. The increased experimental bending displacement may have been caused by additional eccentricity in the test setup from aspects such as misalignment of the specimen or grips, or uneven thickness distribution in the laminates. Separately, the bending displacement may have been underestimated by the numerical models due to the use of first order solid elements.

A summary of the damage progression with increasing countersink height ratio is shown in Figure 18, Table 7 and Figure 19, where Figure 18 shows fibre compression damage through-thickness, Table 7 shows the applied stress at initiation of fibre compression and tension damage, and Figure 19 shows an example of fibre tension damage at the shear plane. Note that the results in Table 7 correspond to the first instance in any element of fibre damage (damage index becomes non-zero), and not to where the element is completely damaged (damage index equals 1). These results all show that increasing the height ratio decreased and delayed the bearing damage whilst causing the fibre tension 
damage at the side of the hole to increase and occur earlier. In the experimental tests, this effect was such that the largest height ratio failed in tension at the side of the hole. In the numerical analysis, the specimen failed by a combination of bearing and net tension failure, which is likely caused by the larger bending displacement in the experimental specimen. The numerical results for the damage profile also showed that increasing the height ratio increased the damage at the shear plane. This was further supported by the radial stresses, where increasing the height ratio from 0.56 to 0.64 increased the radial stress at the shear plane by around three times.

\section{Discussion}

The representation of the bearing damage as in-plane softening is an approximation, which critically does not account for the effect of delamination. The experimental results showed that shear cracking and delamination development are closely related, with the development and progression of one damage mode affecting the other. This interaction is difficult to represent in numerical models, and even micro-mechanical analysis would require significant simplification and assumptions. Despite this, delamination was not thought to significantly contribute to the overall damage development for the specimens investigated, and the numerical results with delamination showed only a small effect on the load-carrying behaviour.

Similarly, in this work, delamination was only investigated at the start of the countersink region, which is the location where it was observed experimentally. Whilst useful for investigating the delamination at this interface, this approach does not reveal whether other ply interfaces would also be predicted to show delamination growth. A more 
broad investigation would study the delamination characteristics of all interfaces, and allow for delamination growth at multiple sites.

The use of two unidirectional plies to represent a woven fabric requires calculation of equivalent unidirectional properties, which in this work was achieved with micromechanical equations and calibration with experimental test results. However, this is approach is only approximate, and is not capable of accounting for fibre undulation and other fabric phenomena. The transverse behaviour of a single unidirectional ply is also different to half a woven ply. The use of damage models specifically developed for fabric materials may be more suitable for analysis purposes. However, the use of the bearing tests results for calibration, the approximate nature of the damage modelling and the use of homogenised material properties mean that a fabric damage model may not offer substantial improvements in numerical predictions. This would require further investigation across different materials and loading conditions, particularly for numerical approaches where calibration and homogenisation are not incorporated.

It is expected that significant improvements in the analysis could be achieved with the use of three-dimensional elements and damage models. Although the success of the numerical predictions using in-plane softening was demonstrated, there are many aspects of the model that could benefit from capturing through-thickness behaviour more accurately. A damage model affecting through-thickness properties would allow through-thickness softening to be captured, though failure criteria and accurate material properties would be more challenging than for in-plane failure. More accurate capturing of through-thickness behaviour would also affect the use of interface elements such as cohesive elements, and 
ensure that more accurate stresses are predicted at the ply interfaces. The representation of bolt torque using through-thickness displacement may also be more suitable, and possibly allow for improved predictions of the bearing stress and the effect of bolt torque.

The issue of convergence and analysis stability was important, as the large element distortion following material failure was problematic for the analysis solver. Further investigation of element controls such as maximum damage index and element deletion, and analysis controls governing convergence and stability criteria would be beneficial in any future analysis. Furthermore, the use of ply-level element discretisation through the thickness may also be beneficial, as currently element deletion is only possible once failure of all plies within an element occurs. As such, failure in some plies within an element may lead to element distortion, while the existence of other undamaged plies within the same element could prevent element deletion.

\section{Conclusion}

The strength and damage progression of composite countersunk single lap joints has been investigated using numerical analysis. The computational model was developed by using continuum shell elements with an in-plane progressive damage model and cohesive elements to describe three major failure modes: bearing failure, net section fracture, and delamination. The critical property of fibre compressive failure toughness was calibrated using experimental test data from straight-edge hole bearing tests. The remaining material properties were determined from published data for the material being used in the present investigation. The complex contact conditions between the laminates and bolt-nut assembly 
were modelled, including friction. Bolt torque was represented with an equivalent throughthickness displacement.

The analysis methodology was shown to give close agreement with experimental results, in terms of load-carrying capability and damage patterns. The numerical results replicated the trends observed in the experimental results, and also provided rich insight into the damage progression and joint performance. Increasing bolt torque was found to increase damage in the countersunk area whilst reducing it close to the shear plane, without affecting the distribution of damage around the hole. The change in damage behaviour with the introduction of clearance was shown to be caused by the reduction in contact area, which increased stresses and localised the damage close to the shear plane. The increased bending and net-tension failure associated with increasing the relative height of the countersunk region was clearly demonstrated. The influence of delamination was shown to be minimal in terms of the load-carrying capability and occurrence of bearing damage.

\section{Acknowledgements}

The authors acknowledge the financial support provided by the Australian Postgraduate Award. The computing facilities provided by the Victorian Partnership for Advanced Computing (VPAC) and RMIT-HPC are also acknowledged. 


\section{References}

[1] Chishti M, Wang CH, Thomson RS, Orifici AC. Experimental investigation of damage progression and strength of countersunk composite joints. Composite Structures. 2011;(submitted February 2011).

[2] Chishti M, Wang CH, Thomson RS, Orifici AC. Progressive damage in single lap countersunk composite joints. 9th World Congress on Computational Mechanics and 4th Asian Pacific Congress on Computational Mechanics. Sydney, Australia, 19-23 July, 2010.

[3] Abaqus ${ }^{\circledR}$ 6.9 Documentation. Providence, RI, USA: Dassault Systèmes Simulia Corporation; 2010.

[4] Lapczyk I, Hurtado JA. Progressive damage modeling in fiber-reinforced materials. Composites Part A: Applied Science and Manufacturing. 2007;38:2333-41.

[5] Chamis CC. Simplified composite micromechanics equation for mechanical, thermal and moisture-related properties. In: Weeton JW, Peters DM, Thomas KL, editors. Engineers Guide to Composite Materials: ASM International, OH, USA; 1987.

[6] Jackson WC, Ratcliffe JG. Measurement of fracture energy for kink-band growth in sandwich specimens. Composites Testing and Model Identification. Bristol, UK, 21-23 September, 2004. 
[7] Pinho ST, Robinson P, Iannucci L. Fracture toughness of the tensile and compressive fibre failure modes in laminated composites. Composites Science and Technology. 2006;66:2069-79.

[8] Camanho PP, Dávila CG, de Moura MF. Numerical simulation of mixed-mode progressive delamination in composite materials. Journal of Composite Materials. $2003 ; 37: 1415-38$.

[9] Kim M. Impact resistance of composite scarf joints under load: MEng thesis, RMIT University, Melbourne, Australia, 2010.

[10] Turon A, Dávila CG, Camanho PP, Costa J. An engineering solution for mesh size effects in the simulation of delamination using cohesive zone models. Engineering Fracture Mechanics. 2007;74:1665-82.

[11] Tserpes KI, Papanikos P, Kermanidis T. A three-dimensional progressive damage model for bolted joints in composite laminates subjected to tensile loading. Fatigue $\&$ Fracture of Engineering Materials and Structures. 2001;24:663-75.

[12] Budynas RG, Nisbett JK, Shigley JE. Shigley's Mechanical Engineering Design, 5th edition. NY, USA: McGraw-Hill, 1989.

[13] ASTM D5961, Standard test method for bearing response of polymer matrix composite laminates. American Society for Testing and Materials; 2007. 


\section{Figure Captions}

Figure 1: Countersunk joint geometry and dimensions (mm), strain gauge locations and extensometer tabs

Figure 2: Calibration of fibre compression fracture toughness $\left(\mathrm{kJ} / \mathrm{mm}^{2}\right)$ using bearing test results

Figure 3: Loading steps to apply bolt torque

Figure 4: Mesh. (a) Nominal in-plane mesh. (b) In-plane mesh study variants

Figure 5: Boundary conditions. (a) Bearing test (b) Single-lap joint.

Figure 6: Bearing test, force-displacement, in-plane mesh density analysis.

Figure 7: Cross-section labelling and coordinate systems

Figure 8: Countersunk joints, stress-displacement, experimental and numerical

Figure 9: BT_0 upper laminate, cross-section at $\theta=0^{\circ}$. Left: Experimental micrograph.

Right: Numerical fibre compressive failure damage index

Figure 10: Fibre compression damage index at $2 \mathrm{~mm}$ applied displacement, BT configurations

Figure 11: Fibre compression damage index in upper laminate at $2 \mathrm{~mm}$ applied displacement, selected $0^{\circ}$ plies, BT configurations

Figure 12: Stress-displacement for BT_0 joint, experiment and numerical models with and without delamination

Figure 13: BT 0 joint numerical analysis with stress, fibre compression (FC) and delamination damage index 
Figure 14: Fibre compression damage index at bearing stress, CL configurations Figure 15: Fibre compression damage index in upper laminate at $2 \mathrm{~mm}$ applied displacement, selected $0^{\circ}$ plies, $C L$ configurations Figure 16: Normalised radial stress, CL configurations Figure 17: Out-of-plane (z) displacement at $2 \mathrm{~mm}$ applied displacement, HT configurations Figure 18: Fibre compression damage index at $2 \mathrm{~mm}$ applied displacement, HT configurations

Figure 19: Fibre tension damage index, upper laminate shear plane, $2 \mathrm{~mm}$ applied displacement, HT_0.76 configuration 
Table 1: Specimen dimensions ( $\mathrm{mm})$

\begin{tabular}{|l|l|l|l|l|}
\hline & $t$ & Layup & $D$ & $A$ \\
\hline Bearing & 3.52 & {$[0,45]_{4 \mathrm{~S}}$} & 6.35 & $\mathrm{n} / \mathrm{a}$ \\
\hline BT (all) & 3.52 & {$[0,45]_{4 \mathrm{~S}}$} & 4.76 & 9.56 \\
\hline CL (all) & 3.52 & {$[0,45]_{4 \mathrm{~S}}$} & 4.76 & 9.56 \\
\hline HT_0.56 & 3.52 & {$[0,45]_{4 \mathrm{~S}}$} & 4.76 & 9.56 \\
\hline HT_0.64 & 3.08 & {$\left[(0,45)_{3}, 0\right]_{\mathrm{S}}$} & 4.76 & 9.56 \\
\hline HT_0.76 & 3.52 & {$[0,45]_{4 \mathrm{~S}}$} & 6.35 & 12.71 \\
\hline
\end{tabular}

Table 2: Specimen details

\begin{tabular}{|l|l|l|l|l|}
\hline & Bolt torque $(\mathrm{N} \mathrm{m})$ & Clearance $(\mu \mathrm{m})$ & $h / t$ & Number of specimens* \\
\hline Bearing & $\mathrm{n} / \mathrm{a}$ & $\mathrm{n} / \mathrm{a}$ & $\mathrm{n} / \mathrm{a}$ & 4 \\
\hline BT_0 & 0 (finger tight) & 0 & 0.56 & 3 \\
\hline BT_2.1 & 2.103 & 0 & 0.56 & 3 \\
\hline BT_4.2 & 4.206 & 0 & 0.56 & 3 \\
\hline CL_0 & 2.103 & 0 & 0.56 & 3 \\
\hline CL_240 & 2.103 & 240 & 0.56 & 3 \\
\hline CL_440 & 2.103 & 440 & 0.56 & 3 \\
\hline HT_0.56 & 2.103 & 0 & 0.56 & 3 \\
\hline HT_0.64 & 2.103 & 0 & 0.64 & 3 \\
\hline HT_0.76 & 2.103 & 0 & 0.76 & 3 \\
\hline
\end{tabular}

*BT_2.1, CL_0 and HT_0.56 all represent the same configuration and the same specimens 
Table 3: Material properties for the UD ply

\begin{tabular}{|l|l|l|l|}
\hline Property & Value & Property & Value \\
\hline$E_{11}$ & $84.7 \mathrm{GPa}$ & $X_{T}$ & $1009 \mathrm{MPa}$ \\
\hline$E_{22}$ & $5.22 \mathrm{GPa}$ & $X_{C}$ & $865 \mathrm{MPa}$ \\
\hline$G_{12}$ & $2.41 \mathrm{GPa}$ & $Y_{T}$ & $81 \mathrm{MPa}$ \\
\hline$G_{13}$ & $2.41 \mathrm{GPa}$ & $Y_{C}$ & $188 \mathrm{MPa}$ \\
\hline$G_{23}$ & $1.88 \mathrm{GPa}$ & $S_{12}$ & $69 \mathrm{MPa}$ \\
\hline$v_{12}$ & 0.3 & $S_{13}$ & $69 \mathrm{MPa}$ \\
\hline$v_{13}$ & 0.3 & $S_{23}$ & $62 \mathrm{MPa}$ \\
\hline$v_{23}$ & 0.381 & $\rho$ & $1.6 \mathrm{~g} / \mathrm{cm}^{3}$ \\
\hline
\end{tabular}

Table 4: Calibrated fracture toughness values $\left(\mathrm{kJ} / \mathrm{mm}^{2}\right)$ for the UD ply

\begin{tabular}{|l|l|}
\hline Property & Value \\
\hline$G_{f t}$ & 64 \\
\hline$G_{f c}$ & 55 \\
\hline$G_{m t}$ & 0.15 \\
\hline$G_{m c}$ & 0.45 \\
\hline
\end{tabular}


Table 5: Cohesive element properties

\begin{tabular}{|l|l|l|}
\hline Property & Value & Reference \\
\hline$K_{I}$ & $10^{6} \mathrm{~N} / \mathrm{mm}$ & {$[8,9]$} \\
\hline$K_{I I}$ & $10^{6} \mathrm{~N} / \mathrm{mm}$ & {$[8,9]$} \\
\hline$K_{I I I}$ & $10^{6} \mathrm{~N} / \mathrm{mm}$ & {$[8,9]$} \\
\hline$\sigma_{\max , I}$ & $20 \mathrm{MPa}$ & Equation from $[10]$ \\
\hline$\sigma_{\max , I I}$ & $40 \mathrm{MPa}$ & Equation from $[10]$ \\
\hline$\sigma_{\max , I I I}$ & $40 \mathrm{MPa}$ & Equation from $[10]$ \\
\hline$G_{I}$ & $0.258 \mathrm{~kJ} / \mathrm{mm}^{2}$ & {$[9]$} \\
\hline$G_{I I}$ & $1.08 \mathrm{~kJ} / \mathrm{mm}^{2}$ & {$[9]$} \\
\hline$G_{I I I}$ & $1.08 \mathrm{~kJ} / \mathrm{mm}^{2}$ & {$[9]$} \\
\hline
\end{tabular}


Table 6: Results summary, experiment (average) and numerical

\begin{tabular}{|l|l|l|l|l|l|l|}
\hline & \multicolumn{5}{|l}{ Bearing stress (MPa) } & \multicolumn{2}{l}{ Maximum stress (MPa) } \\
\hline & Experiment & Numerical & Difference & Experiment & Numerical & Difference \\
\hline Bearing & 409 & 447 & $9 \%$ & 571 & 572 & $0.2 \%$ \\
\hline BT_0 & 143 & 125 & $-12 \%$ & 624 & 615 & $-1 \%$ \\
\hline BT_2.1 & 190 & 143 & $-25 \%$ & 646 & 666 & $3 \%$ \\
\hline BT_4.2 & 184 & 143 & $-22 \%$ & 669 & 676 & $1 \%$ \\
\hline CL_0 & 190 & 143 & $-25 \%$ & $565 *$ & $615 *$ & $9 \%$ \\
\hline CL_240 & 158 & 107 & $-32 \%$ & $500 *$ & $534 *$ & $7 \%$ \\
\hline CL_440 & 147 & 107 & $-27 \%$ & $451^{*}$ & $491 *$ & $9 \%$ \\
\hline HT_0.56 & 190 & 143 & $-25 \%$ & $565 *$ & $615 *$ & $9 \%$ \\
\hline HT_0.64 & 192 & 143 & $-25 \%$ & $559 *$ & $636 *$ & $14 \%$ \\
\hline HT_0.76 & 107 & 134 & $25 \%$ & $471 *$ & $493 *$ & $5 \%$ \\
\hline
\end{tabular}

* taken at $2 \mathrm{~mm}$ applied displacement

Table 7: Applied stress (MPa) at damage initiation, HT configurations

\begin{tabular}{|l|l|l|l|}
\hline & HT_0.56 & HT_0.64 & HT_0.76 \\
\hline Fibre compression & 155 & 97 & 85 \\
\hline Fibre tension & 227 & 197 & 128 \\
\hline
\end{tabular}




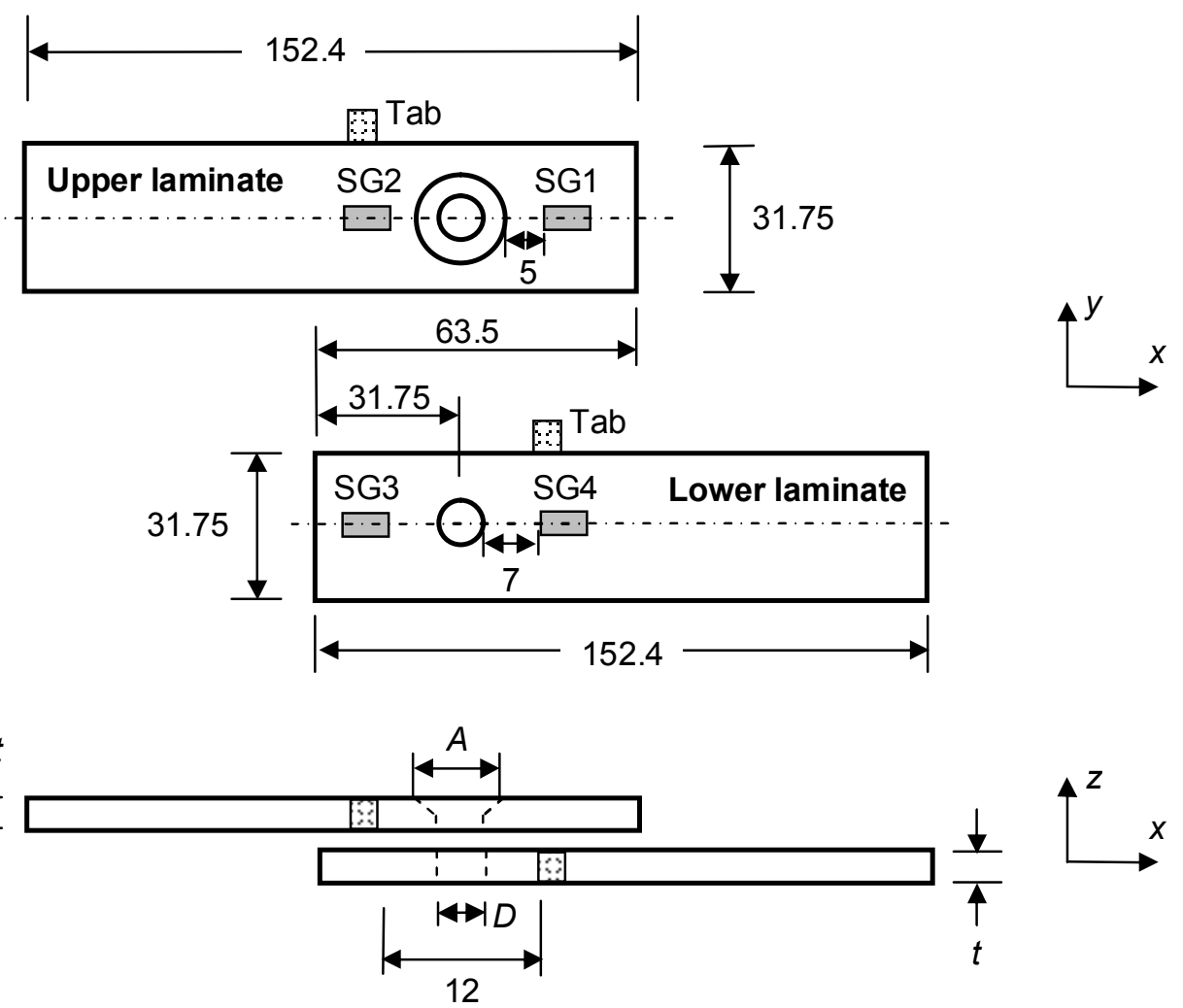

Figure 1: Countersunk joint geometry and dimensions ( $\mathrm{mm})$, strain gauge locations and extensometer tabs. 


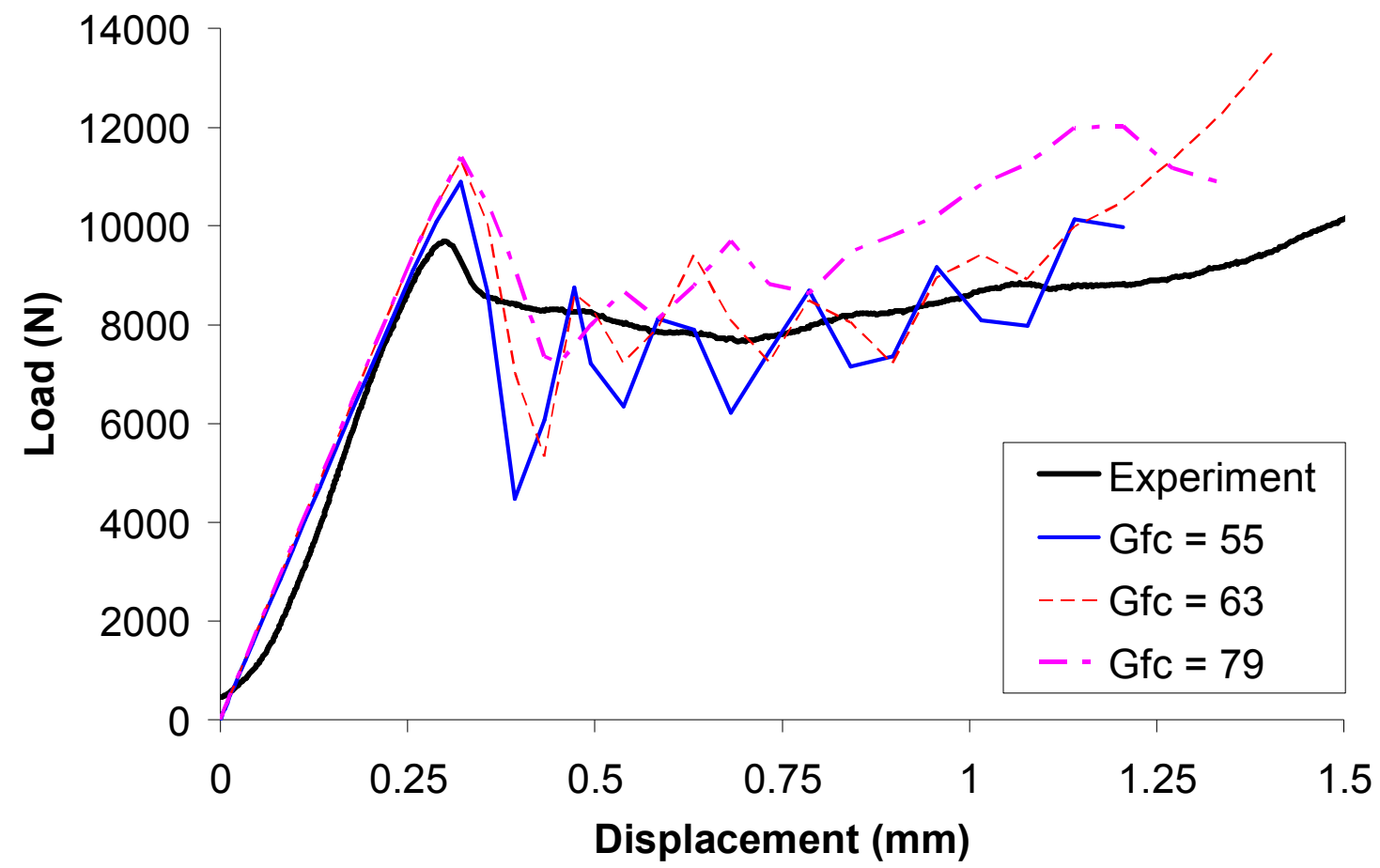

Figure 2: Calibration of fibre compression fracture toughness $\left(\mathrm{kJ} / \mathrm{mm}^{2}\right)$ using bearing test results 


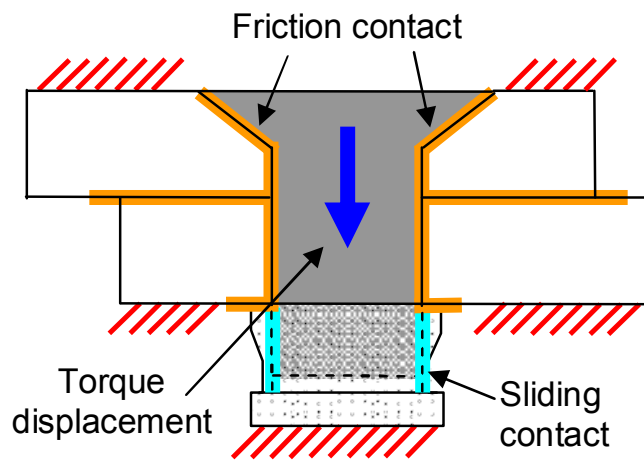

1) Bolt displaced, laminates and nut fixed

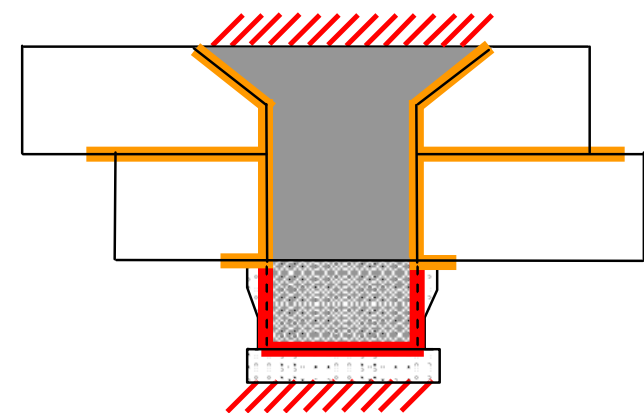

3) Bolt-nut fixed, laminates free

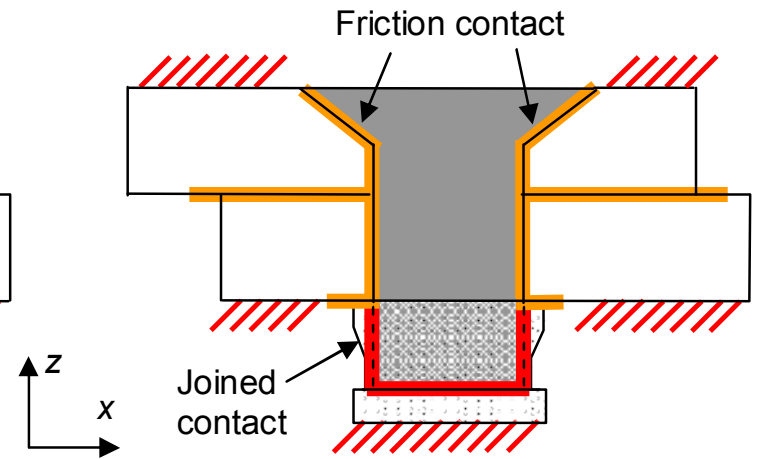

2) Bolt and nut tied, laminates and nut fixed

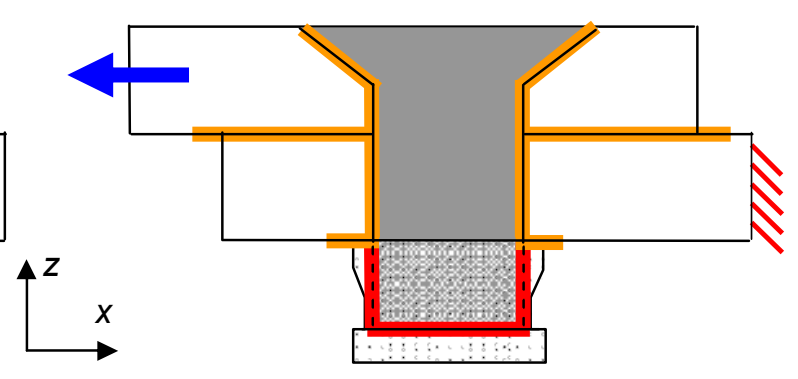

4) Displacement load applied

Figure 3: Loading steps to apply bolt torque. 


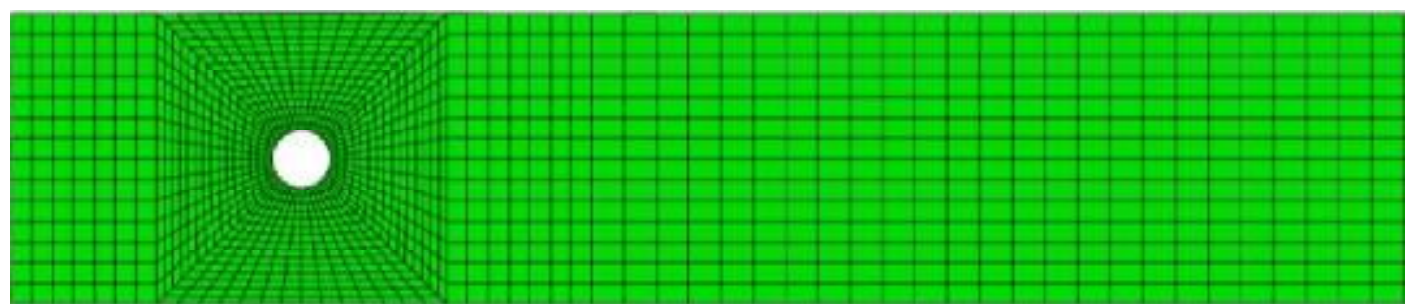

(a)

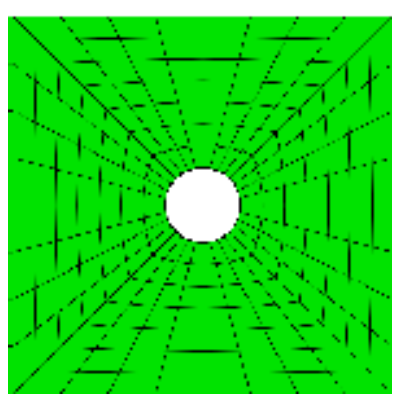

Coarse mesh

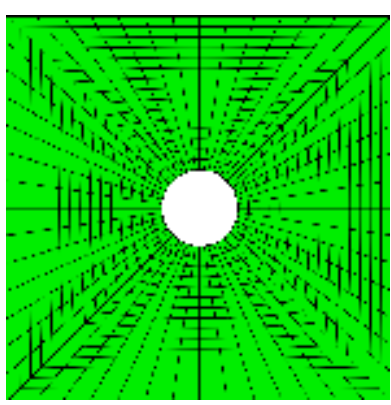

Nominal mesh

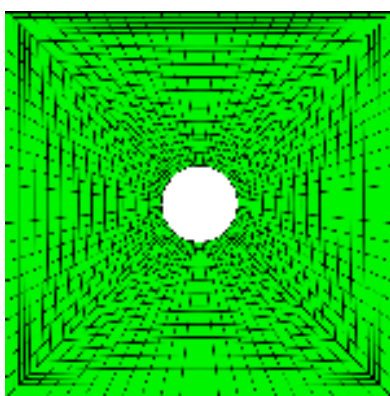

Fine mesh

(b)

Figure 4: Mesh. (a) Nominal in-plane mesh. (b) In-plane mesh study variants.

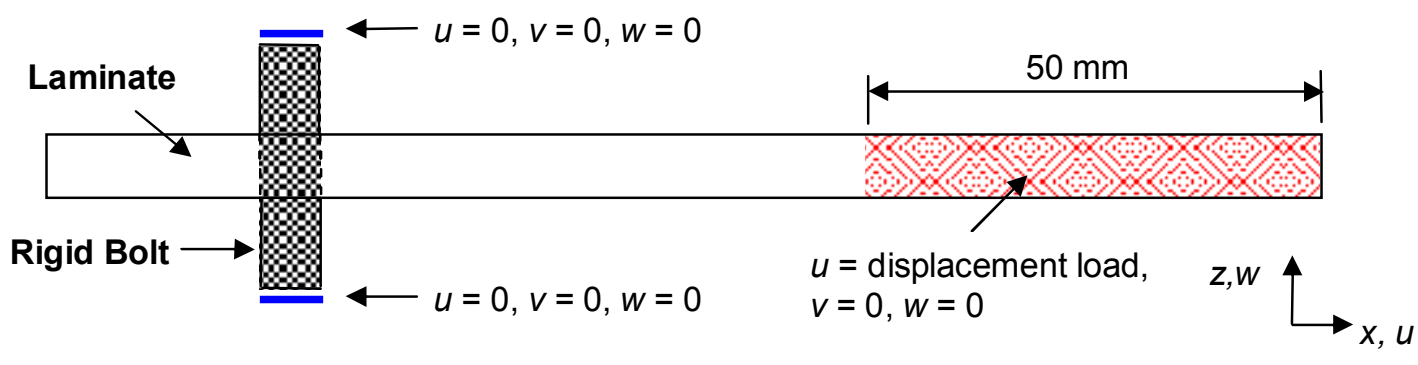

(a)

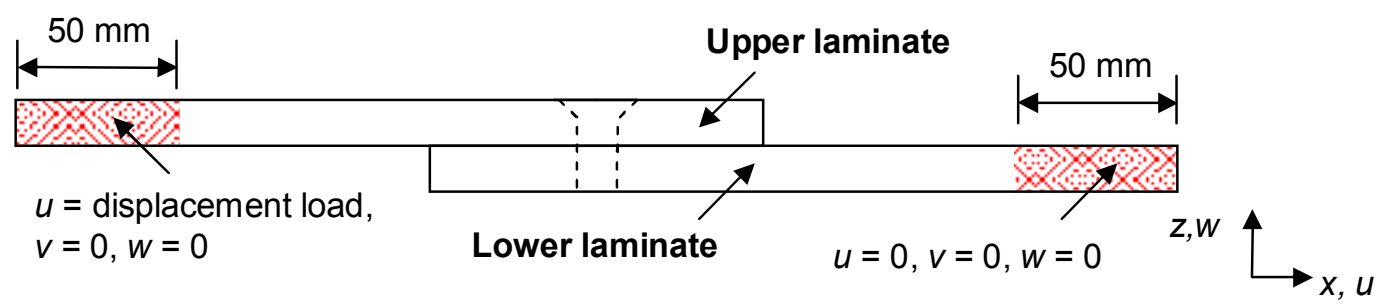

(b)

Figure 5: Boundary conditions. (a) Bearing test (b) Single-lap joint. 


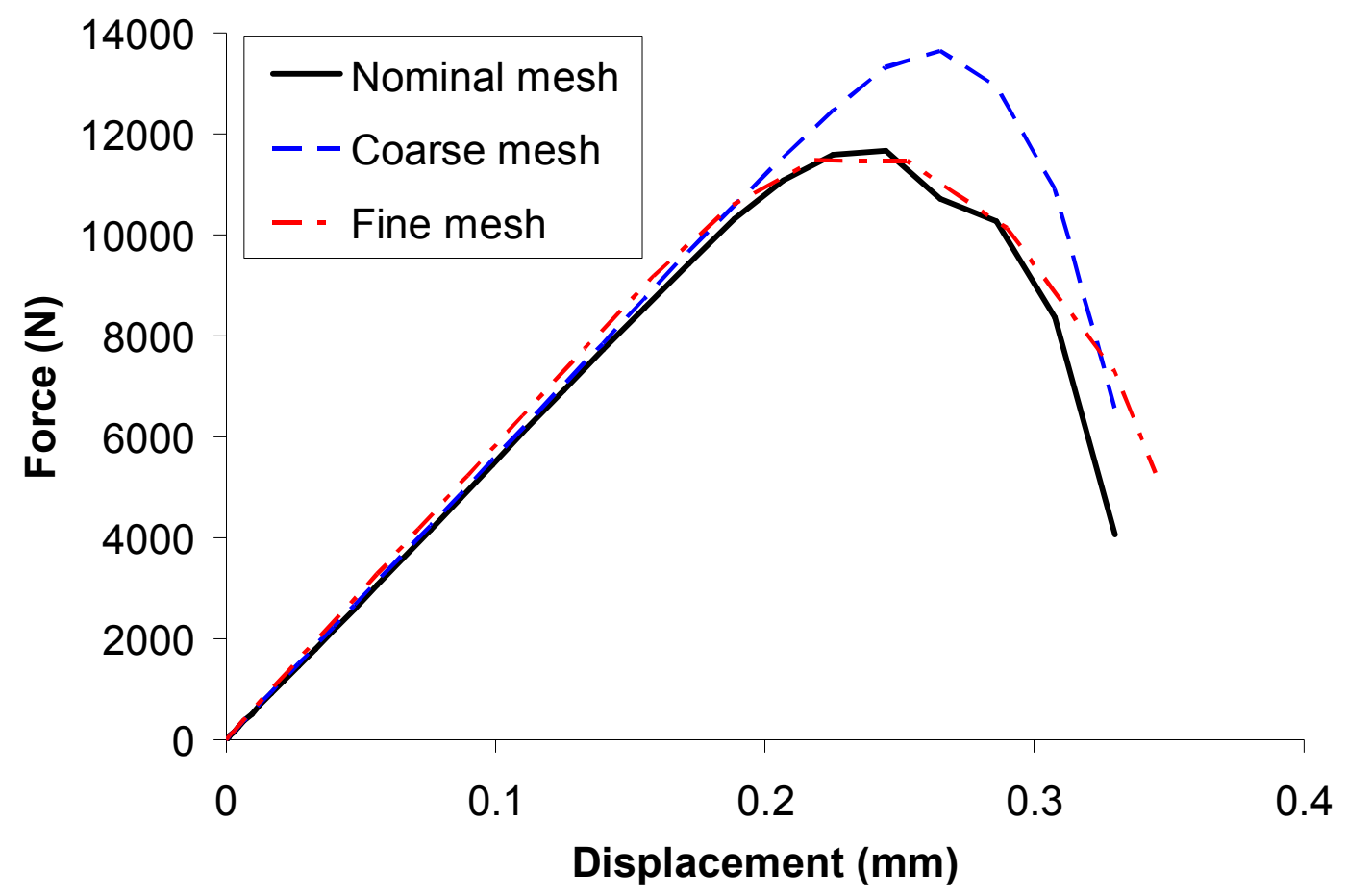

Figure 6: Bearing test, force-displacement, in-plane mesh density analysis.
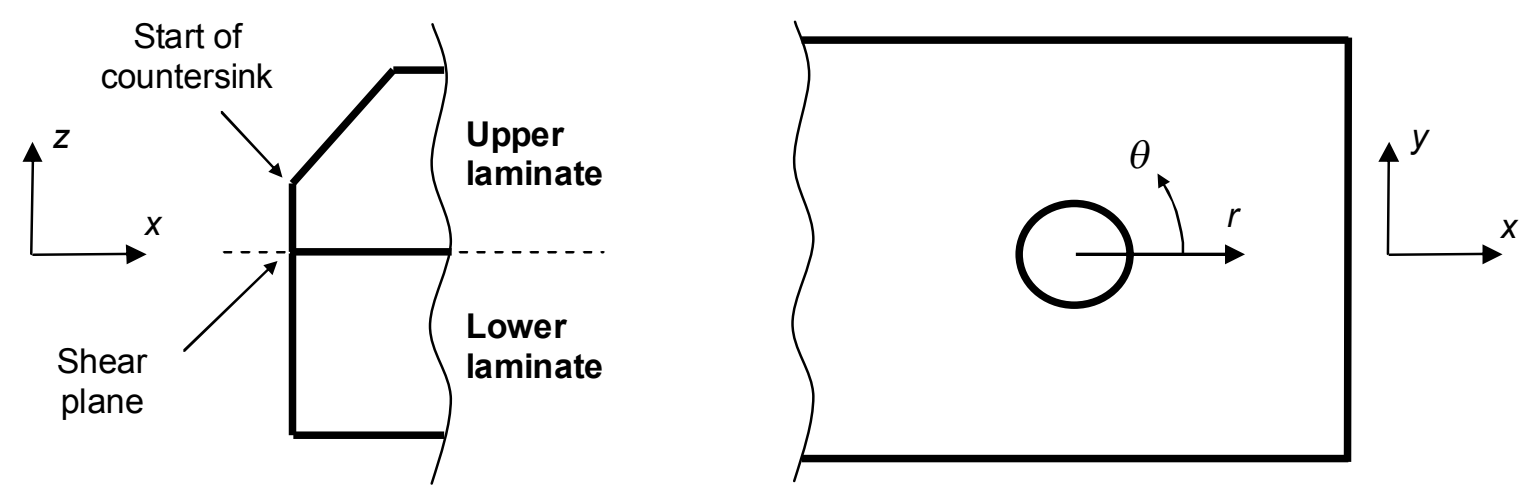

Figure 7: Cross-section labelling and coordinate systems. 


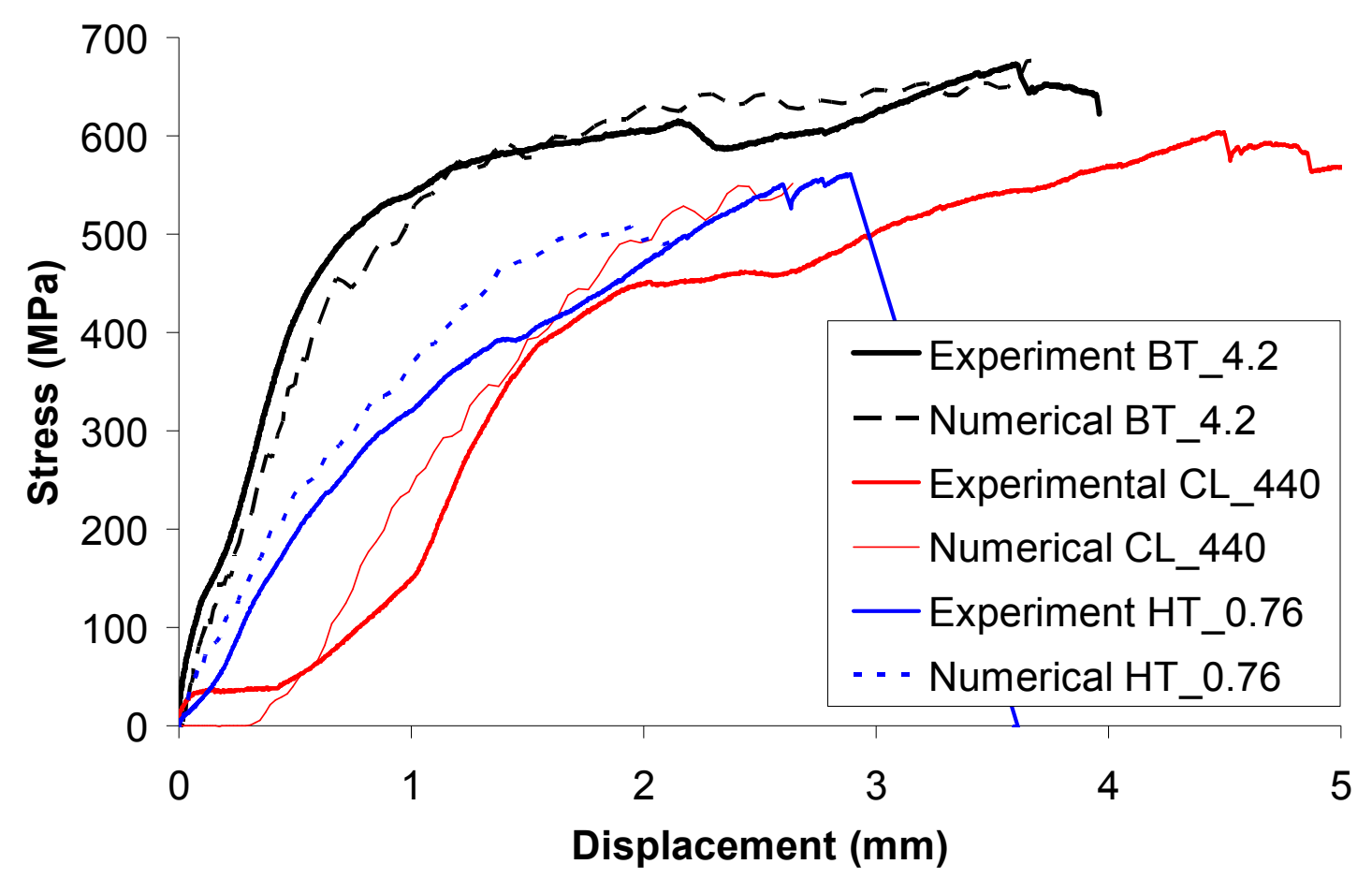

Figure 8: Countersunk joints, stress-displacement, experimental and numerical. 


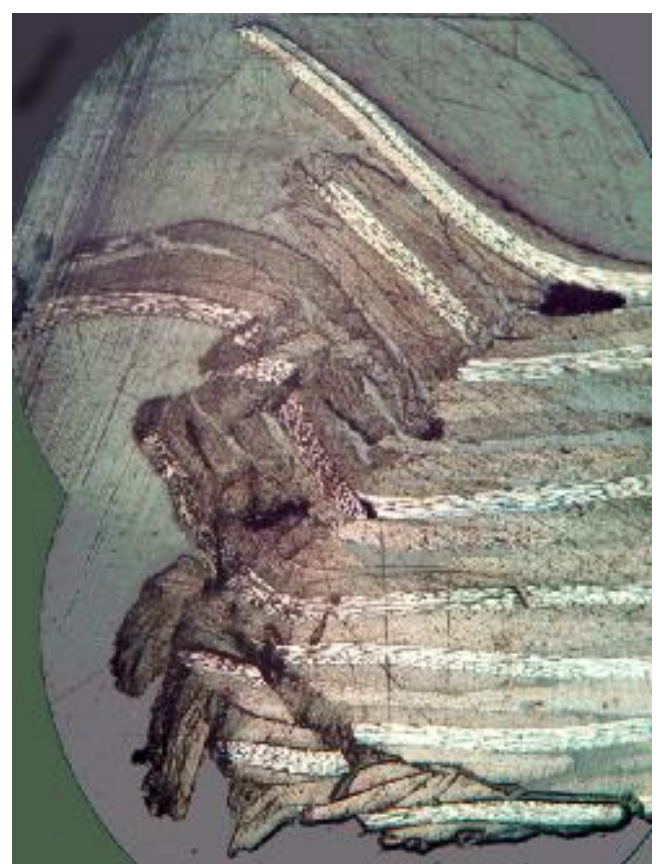

Experiment

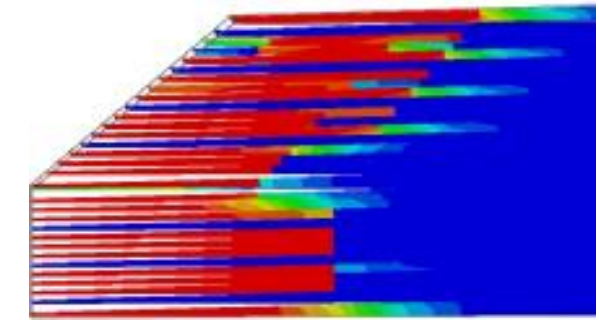

Numerical, ply-by-ply

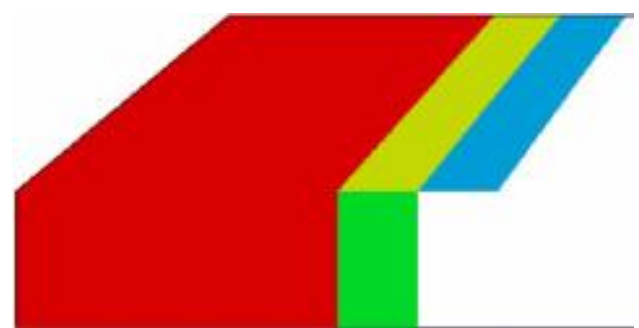

Numerical, enveloped

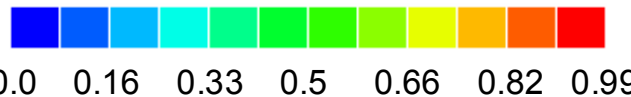

Figure 9: BT_0 upper laminate, cross-section at $\theta=0^{\circ}$. Left: Experimental micrograph. Right: Numerical fibre compressive failure damage index.

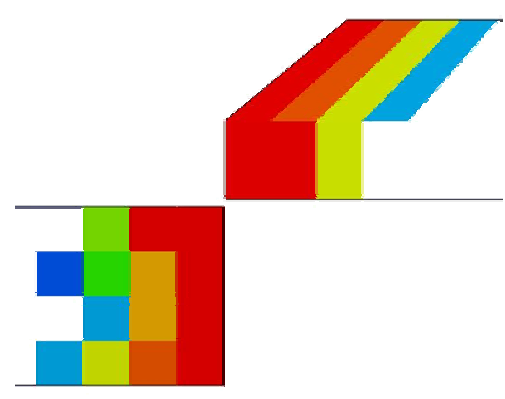

a) BT_0

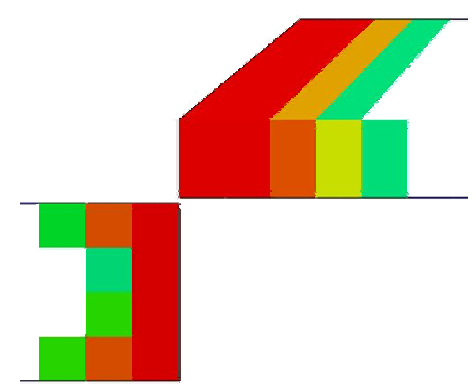

b) BT_2.1

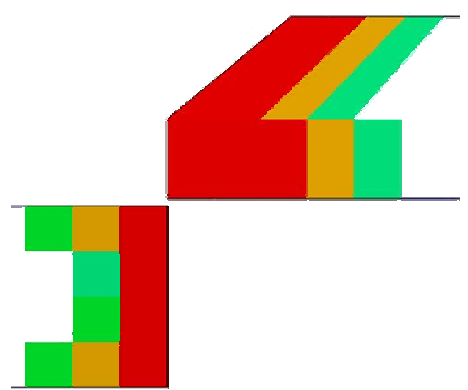

c) BT_4.2

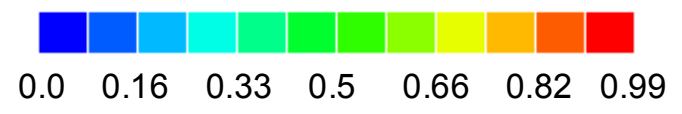

Figure 10: Fibre compression damage index at $2 \mathrm{~mm}$ applied displacement, BT configurations, cross-section at $\theta=0^{\circ}$. 


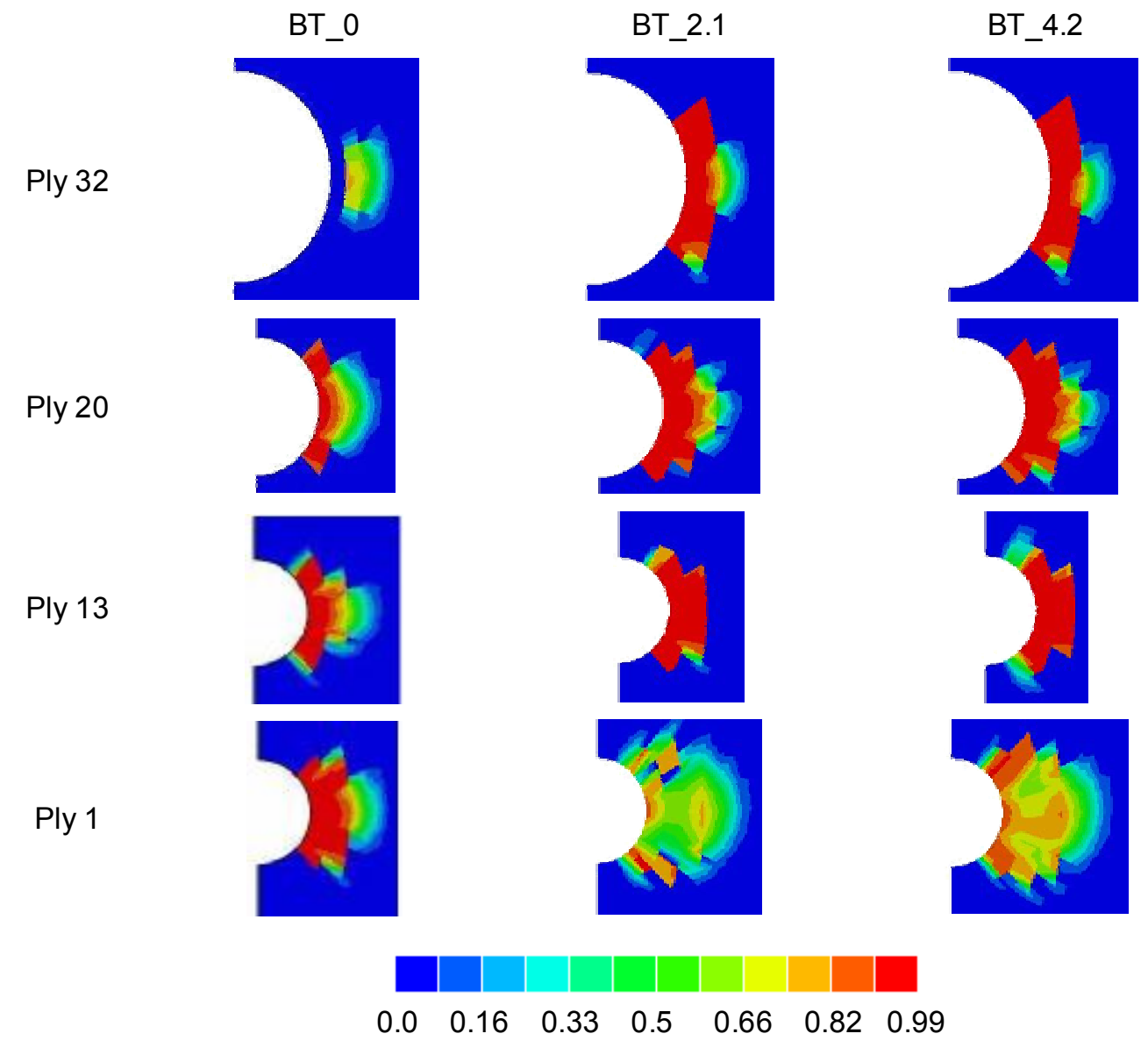

Figure 11: Fibre compression damage index in upper laminate at $2 \mathrm{~mm}$ applied displacement, selected $0^{\circ}$ plies, BT configurations. 


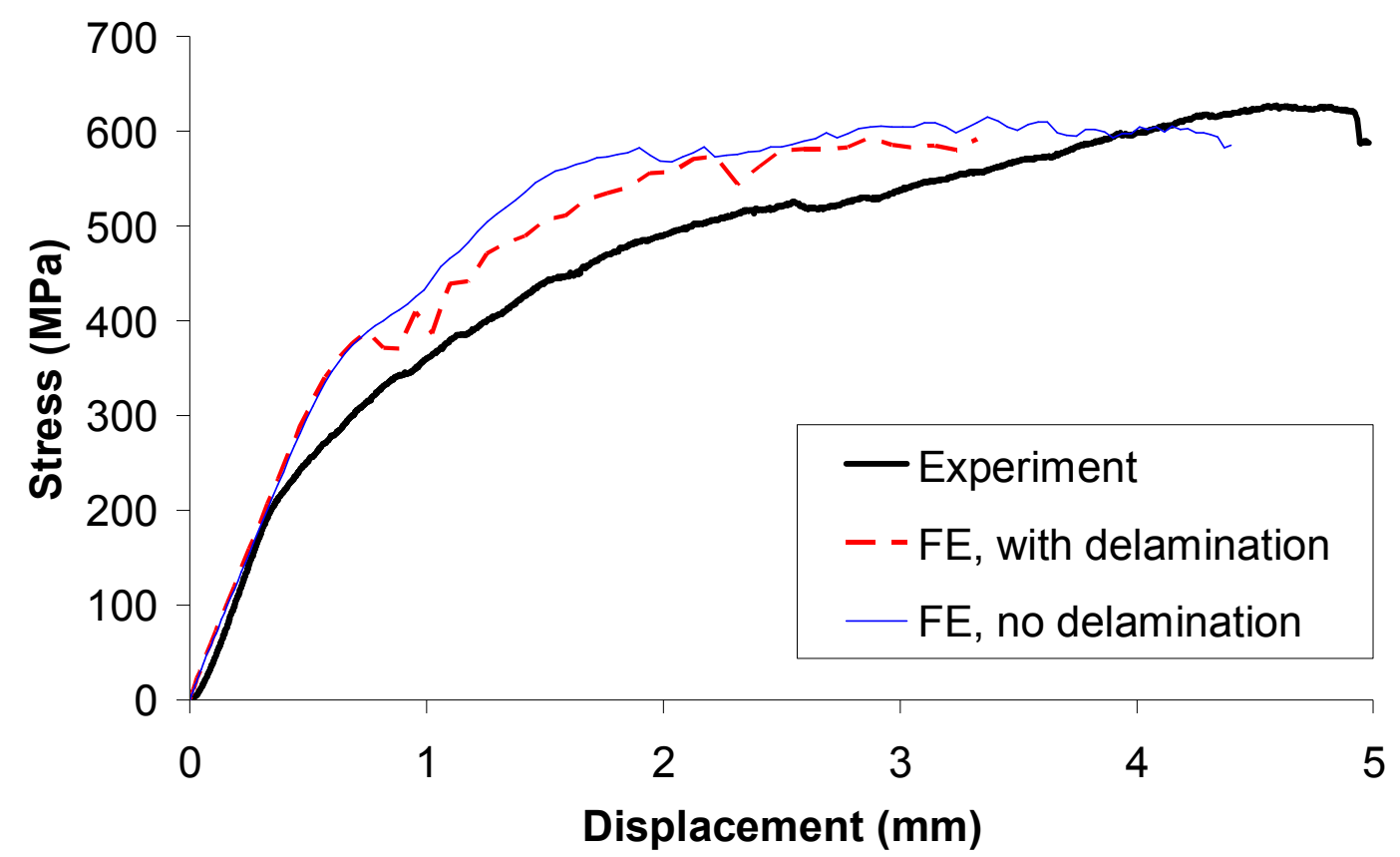

Figure 12: Stress-displacement for BT_0 joint, experiment and numerical models with and without delamination.

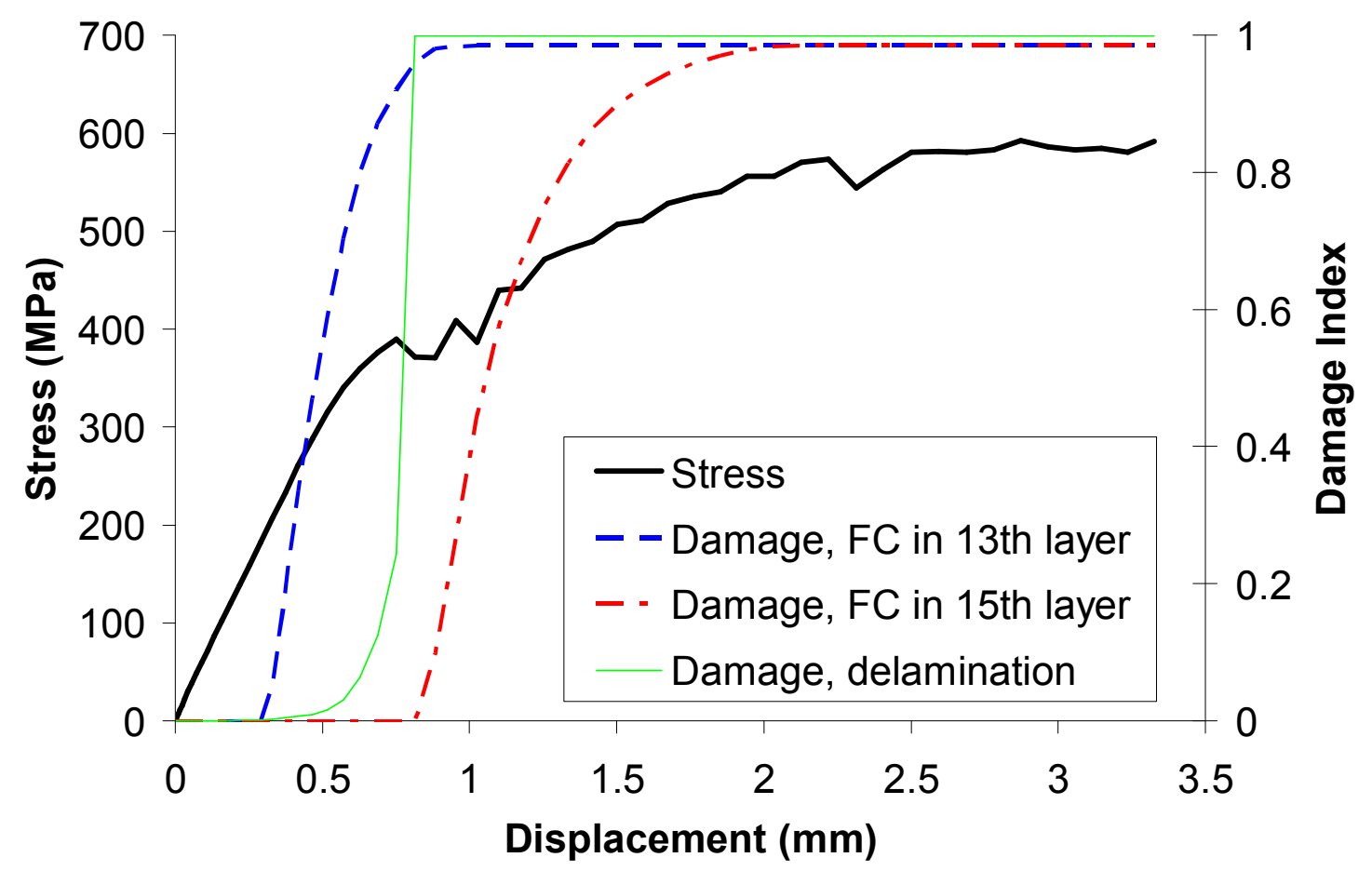

Figure 13: BT_0 joint numerical analysis with stress, fibre compression (FC) and delamination damage index. 


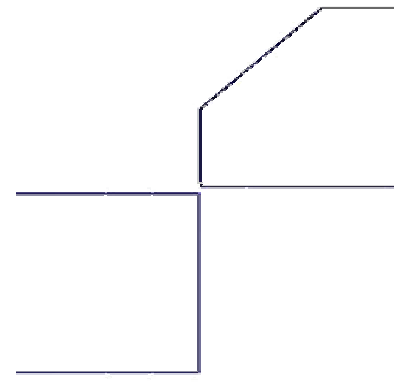

a) $\mathrm{CL}_{-} 0$

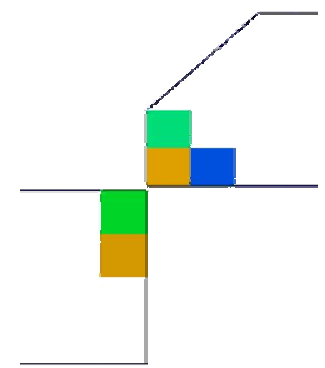

b) $\mathrm{CL} 2240$

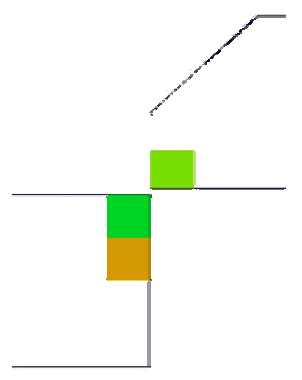

c) $\mathrm{CL} \_440$

$\begin{array}{lllllll}0.0 & 0.16 & 0.33 & 0.5 & 0.66 & 0.82 & 0.99\end{array}$

Figure 14: Fibre compression damage index at bearing stress, CL configurations, crosssection at $\theta=0^{\circ}$.

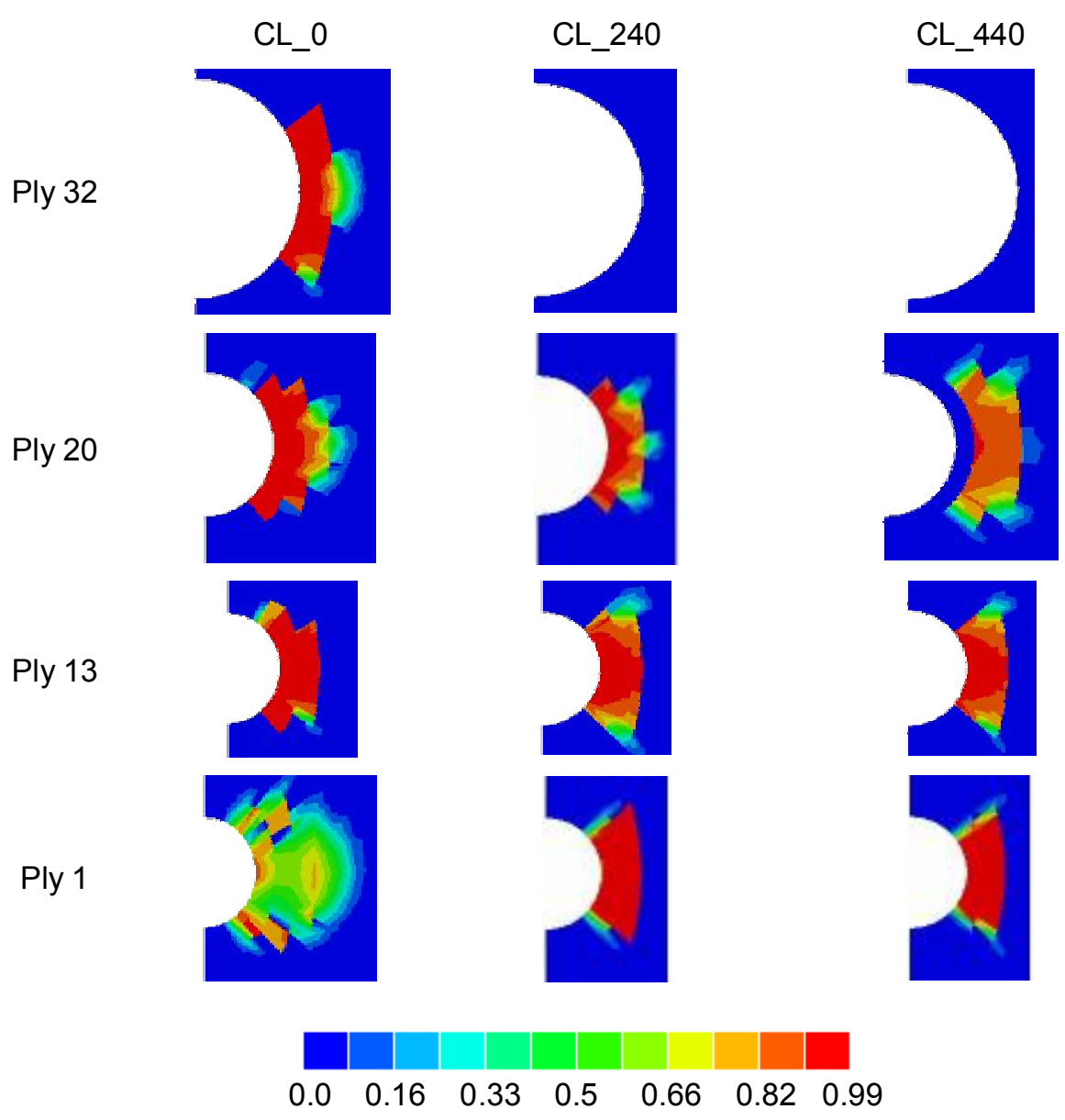

Figure 15: Fibre compression damage index in upper laminate at $2 \mathrm{~mm}$ applied displacement, selected $0^{\circ}$ plies, $C L$ configurations. 


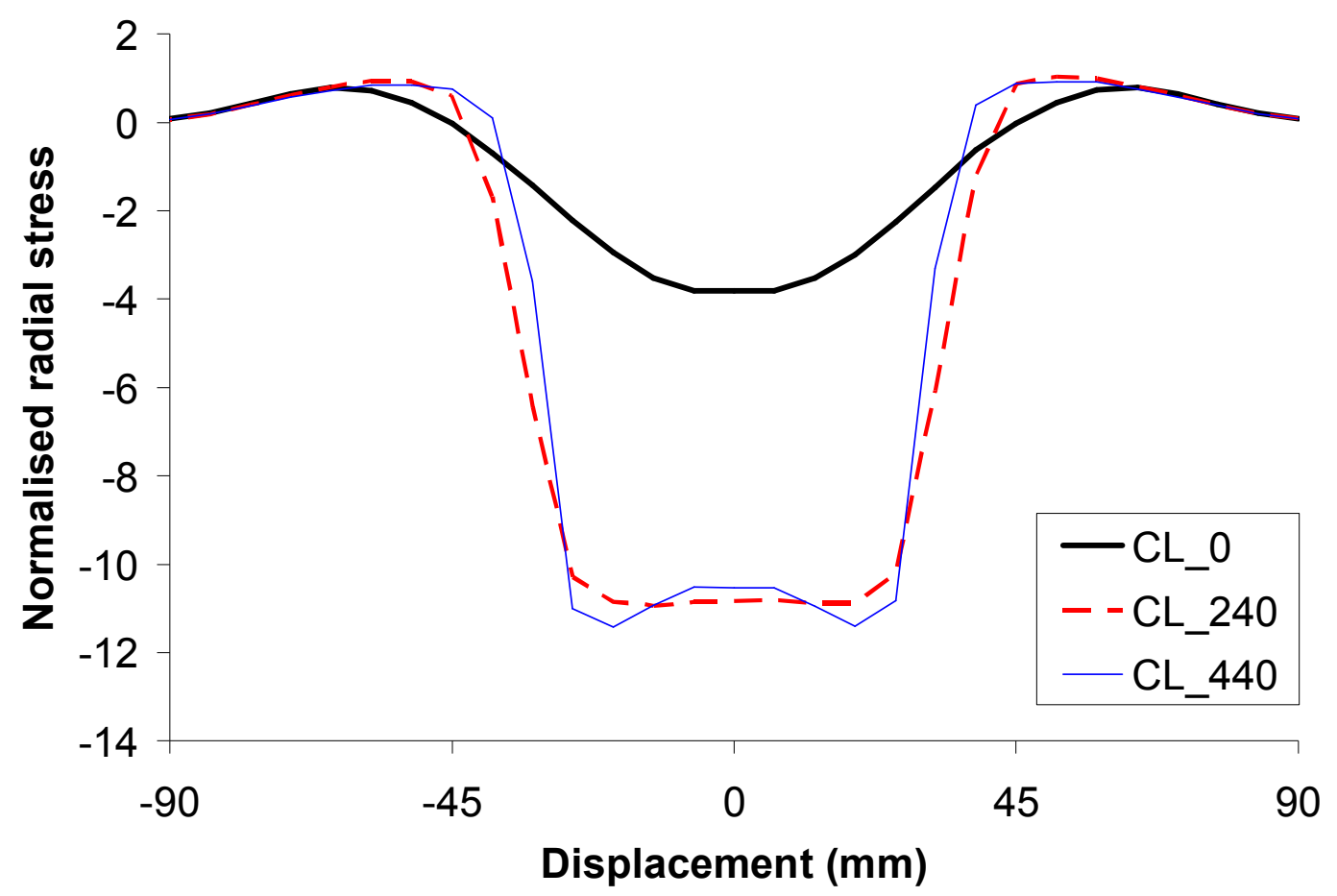

Figure 16: Normalised radial stress, CL configurations.

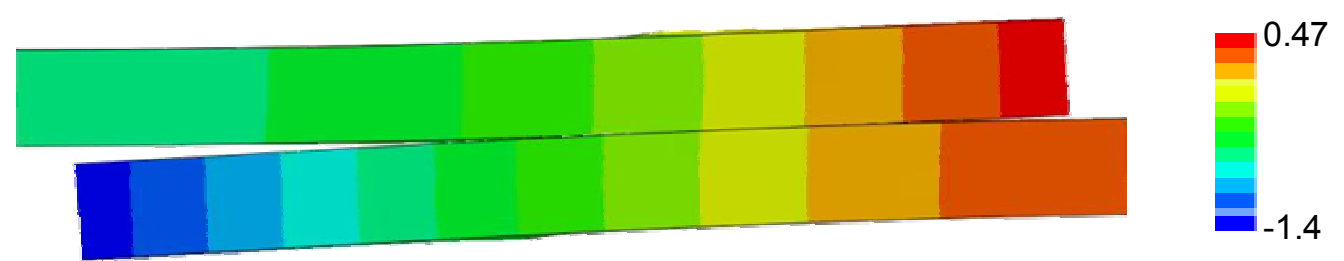

a) HT_0.56

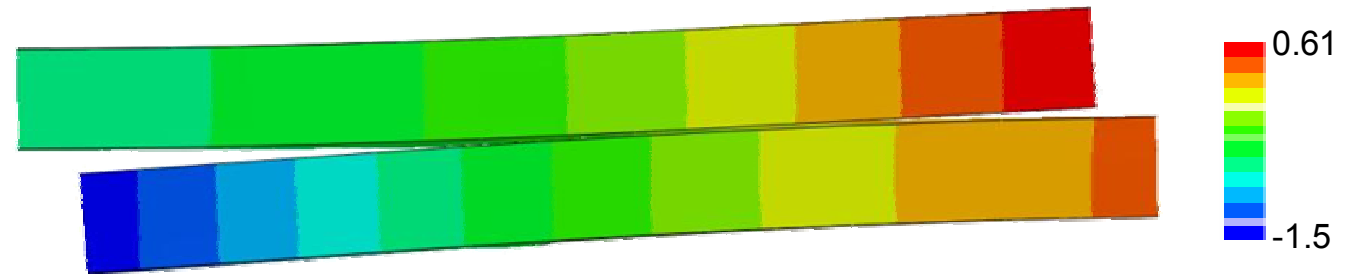

b) HT_0.64

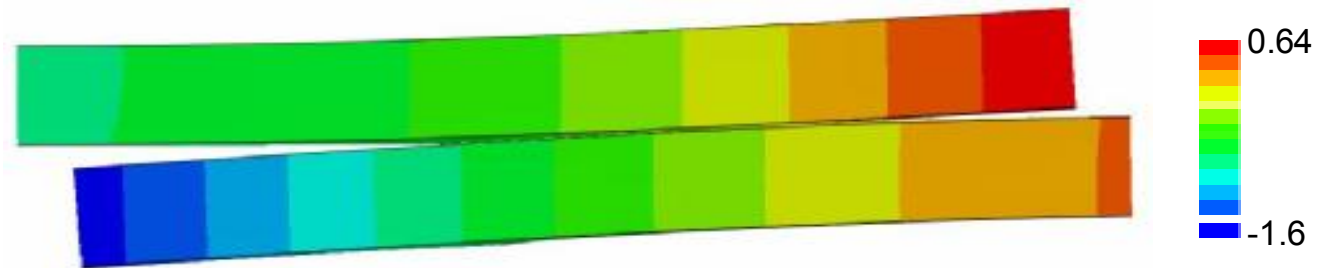

c) HT_0.76

Figure 17: Out-of-plane $(z)$ displacement at $2 \mathrm{~mm}$ applied displacement, HT configurations 


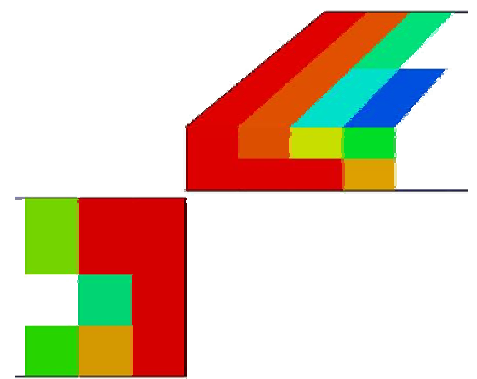

a) HT_0.56

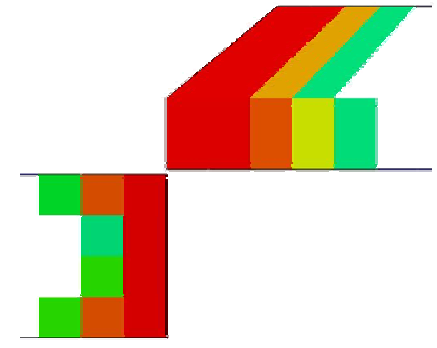

b) HT_0.64

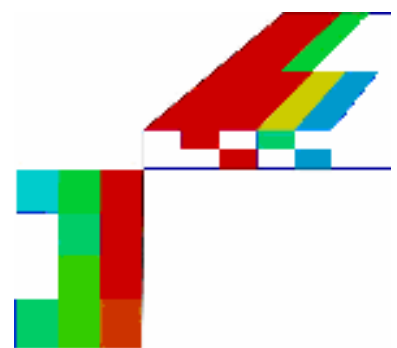

c) HT_0.76

\section{$\begin{array}{lllllll}0.0 & 0.16 & 0.33 & 0.5 & 0.66 & 0.82 & 0.99\end{array}$}

Figure 18: Fibre compression damage index at $2 \mathrm{~mm}$ applied displacement, HT configurations, cross-section at $\theta=0^{\circ}$.
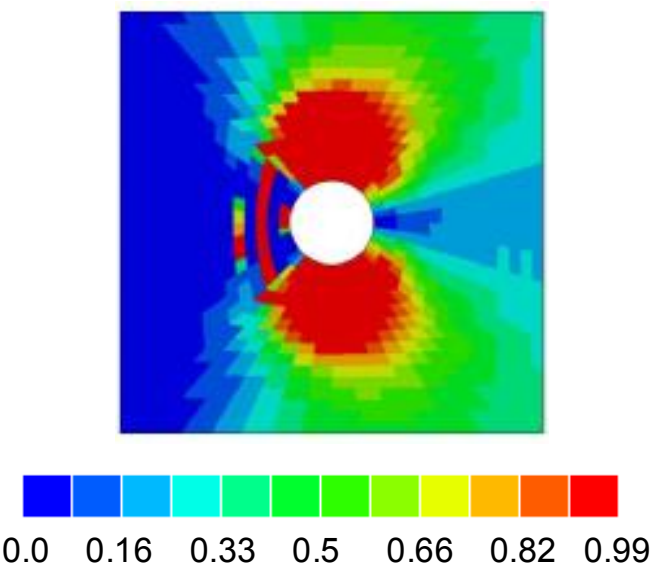

Figure 19: Fibre tension damage index, upper laminate shear plane, $2 \mathrm{~mm}$ applied displacement, HT_0.76 configuration. 